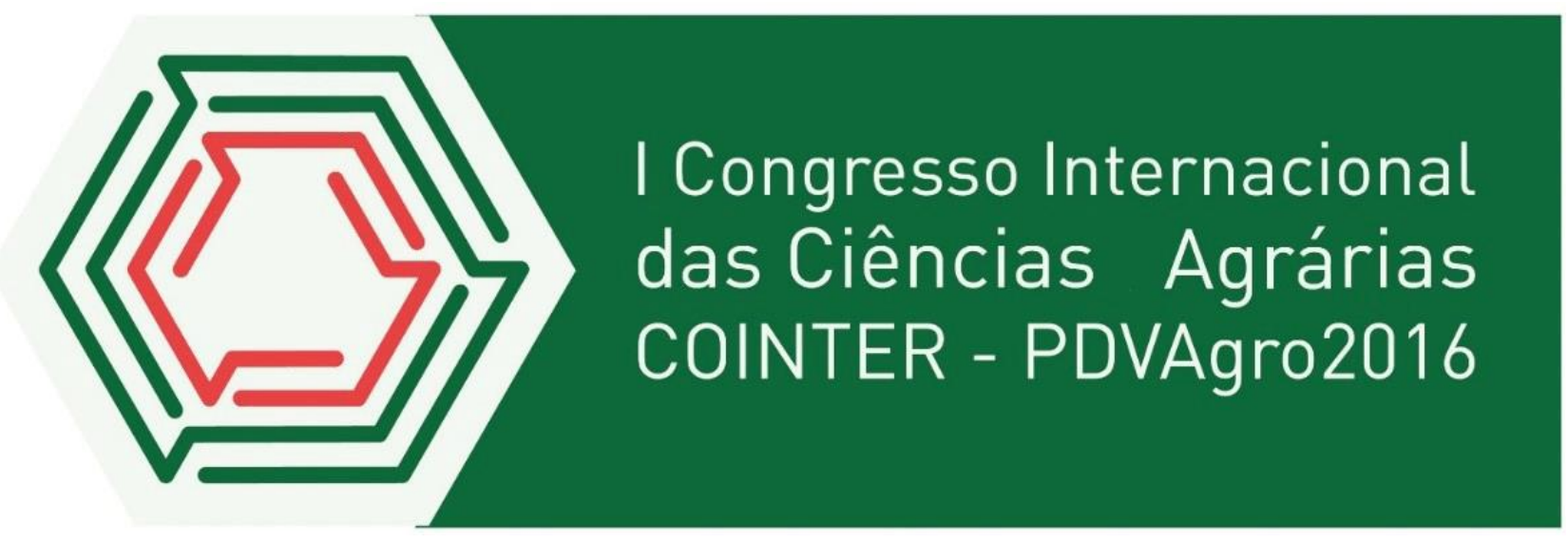

\title{
VARIAÇÃO TEMPORAL NA PRECIPITAÇÃO CAUSA MUDANÇA NA COMPOSIÇÃO FLORÍSTICA, RIQUEZA DE ESPÉCIES E A DENSIDADE DE SEMENTES DO BANCO DO SOLO?
}

Danielle Melo dos Santos ${ }^{1}$; Kleber Andrade da Silva²; Josiene Maria Falcão Fraga dos Santos $^{3}$; Bruno Ayron de Souza Aguiar ${ }^{4}$; Elcida de Lima Araújo ${ }^{5}$

\section{Introdução}

As variações anuais e sazonais que ocorrem na precipitação em função do tempo podem causar mudanças na dinâmica do banco de sementes das florestas secas (ARAÚJO et al., 2013; SANTOS et al., 2013). Entre os atributos mais afetados da comunidade vegetal estão a riqueza de espécies e a densidade de sementes (TRABA et al., 2006 ; SILVA et al., 2013) que em algumas áreas são maiores em anos mais úmidos (FACELLI et al., 2005) em outras áreas são maiores em períodos secos (ONAINDIA e AMEZAGA, 2000). Além disso, as precipitações de anos anteriores também podem ter um maior poder de explicação sobre os atributos do banco de sementes do que as chuvas do ano corrente (SILVA et al., 2013). Portanto, os atributos do banco de sementes do presente pode ser um reflexo da influência da precipitação do passado sobre a dinâmica da comunidade vegetal.

$\mathrm{Na}$ Região Nordeste do Brasil, o tipo predominante de floresta seca é denominado de caatinga, na qual ocorrem baixos totais pluviométricos anuais, irregularidade de distribuição das chuvas (SANTOS et al., 2013; SILVA et al., 2013) que a torna um bom exemplo para verificar o efeito da precipitação do presente e passado. Então, admitindo que a dinâmica do banco de sementes do solo das florestas tropicais secas seja regida pela heterogeneidade temporal, este estudo

\footnotetext{
1,2 Universidade Federal de Pernambuco- Centro Acadêmico de Vitória de Santo-Antão, R. Alto do Reservatório, S/n Bela Vista, Vitória de Santo Antão - PE, danmelo_bio@hotmail.com

3,4 Universidade Federal Rural de Pernambuco, Rua Dom Manoel de Medeiros, Dois Irmãos, Recife-Pe.

${ }^{5}$ Professora Doutora do Departamento de Biologia, Universidade Federal Rural de Pernambuco.
} 
tem por hipótese que: 1) As variações na precipitação, entre estações climáticas e entre anos consecutivos, causam mudanças na composição florística e determinam o número de sementes e de espécies do banco de sementes.

Para testar esta hipótese este estudo se propõe a responder a seguinte pergunta: (1) Os atributos do banco de sementes do solo (Composição florística, riqueza de espécies e a densidade de sementes) são afetados pela variação temporal na precipitação?

\section{Fundamentação Teórica}

O banco de sementes das florestas tropicais secas contribui com a manutenção e renovação das populações de plantas nativas (ARAÚJO et al., 2013). Ele assegura a sobrevivência de determinadas espécies através do armazenamento de sementes que, porventura, não consigam se estabelecer na vegetação (WANG et al., 2005). A riqueza de espécies e a densidade de sementes encontradas no banco do solo variam de acordo com o tempo e com as diferenças espaciais encontradas nesta vegetação (SANTOS et al., 2013).

Durante a estação chuvosa, existe uma maior disponibilidade de água que possibilita uma maior reprodução das plantas e tempo de frutificação das espécies ocorrendo em sincronia com o período chuvoso (WANG et al., 2005). Consequentemente, ocasiona uma maior dispersão das sementes no solo, formando um banco de sementes mais rico e denso neste período (WANG et al., 2005; TRABA et al., 2006). Além disso, sementes de algumas espécies que são dispersas no período seco, podem permanecer dormentes no banco do solo e germinar apenas durante o período chuvoso (WILLIAMS et al., 2005). Também pode ocorrer maior dessecação das sementes no período seco diminuindo a riqueza e o quantitativo de sementes (WILLIAMS et al., 2005; ARAÚJO et al., 2013). Outras Pesquisas também vêm descrevendo que, em alguns locais a densidade de sementes e a riqueza de espécies podem ser maiores em períodos secos (SANTOS et al., 2013; SILVA et al., 2013). Desta forma, tal fato está relacionado à persistência do banco de sementes do solo (ONAINDIA e AMEZAGA, 2000) e, por conseguinte, ao acúmulo da produção de sementes do ano anterior (SILVA et al., 2013) e dispersão de sementes quiescentes de espécies que frutificam apenas na estação seca.

\section{Metodologia}


Caracterização da área de estudo

O estudo foi realizado em uma área de floresta tropical seca, localmente denominada Caatinga, com fisionomia arbustivo-árbórea (ANDRADE-LIMA, 1981; RODAL et al., 1999; SAMPAIO et al., 2005). A área está localizada numa estação de pesquisas experimentais

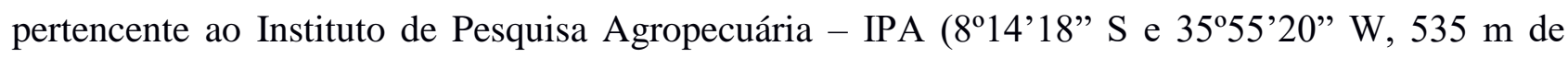
altitude), em Caruaru, PE, Brasil. Os totais de precipitação variaram de 350,8 mm a 1031,2 mm durante os setes anos (2006 a 2012) deste estudo. A estação chuvosa geralmente ocorre entre março e agosto e os demais meses são marcados pela seca.

Amostragens do banco de sementes

No fragmento de vegetação nativa estudada, existe um trecho de 1 ha onde vêm sendo realizados estudos de longo prazo sobre a vegetação local (ARAÚJO et al., 2013; SANTOS et al., 2013; SILVA et al., 2013). No interior desse trecho foram coletadas amostras de solo nos finais das estações chuvosas (Março) e secas (Setembro) durante sete anos consecutivos (2006 a 2012). O solo foi coletado em parcelas confeccionadas com chapa galvanizada de $20 \times 20 \mathrm{~cm}$, a $5 \mathrm{~cm}$ de profundidade, separando a camada de serrapilheira, totalizando 2940 amostras.

Todas as amostras foram acondicionadas em sacos plásticos e etiquetadas por parcela e, em casa de vegetação, cada amostra foi colocada em bandeja de isopor $(20 \times 38 \times 3 \mathrm{~cm})$ e irrigada diariamente, sem adição de solução nutritiva e/ou hormonal por um período de seis meses. A determinação do número de sementes no banco do solo foi realizada pelo método de emergência de plântulas (não considerando o número de sementes dormentes da amostra), sendo a mesma expressa por metro quadrado para possibilitar comparação entre os estudos realizados (WANG et al., 2005; SANTOS et al., 2013; SILVA et al., 2013).

Diariamente, as plântulas emergentes de cada amostra do solo foram contadas e etiquetadas, anotando-se a data de germinação e o número da parcela. A identificação também foi realizada através de consultas em literatura específica e por comparações com exsicatas depositadas nos herbários Prof. Vasconcelos Sobrinho (PEUFR) e Dárdano de Andrade Lima (IPA), adotando-se o sistema de classificação de APG III. Plântulas não identificadas foram indicadas como morfoespécies.

Análises do banco de sementes

A composição florística da floresta foi comparada entre estações climáticas e entre anos 
através da Análise de Escalonamento Multidimensional Não Métrico (NMDS), utilizando a matriz de dissimilaridade Bray-Curtis, com base na densidade relativa das espécies das 105 unidades amostrais da área de estudo. O ANOSIM foi utilizado para verificar a significância do agrupamento formado no NMDS. Para as análises do NMDS e ANOSIM foi utilizado o programa Primer versão 6.1.6.

Modelos lineares generalizados (GLM) foram utilizados para avaliar o efeito das variações sazonais e anuais nas precipitações do presente e do passado sobre a riqueza de espécies e emergência de plântulas do banco de sementes do solo. Todas as análises estatísticas foram feitas com o software livre R.

\section{Resultados e Discussões}

Durante os sete anos deste estudo, um total de 138 espécies emergiu das amostras do banco de sementes do solo. Das 138 espécies, 101 emergiram apenas na estação seca e 102 apenas na estação chuvosa. Trinta e cinco espécies ocorreram exclusivamente na estação seca e 29 na estação chuvosa. A densidade do banco de sementes variou de 1 a 66 sem.m-2. A densidade total do banco de sementes foi 583 sem.m-2 sendo 235 sem.m-2 na estação chuvosa e 348 sem.m-2 na estação seca.

Em relação à composição florística, foi possível constatar que houve variação sazonal ( $R$ global $=0,242$ e $\mathrm{p}<0,01)$ e anual $(\mathrm{R}$ global $=0,209$ e $\mathrm{p}<0,01)$ no conjunto de espécies. $\mathrm{O}$ conjunto de espécies registrado no sétimo ano deste estudo foi diferente, sendo menor, em comparação com os conjuntos registrados nos seis primeiros anos.

A análise GLM mostrou que as variações sazonais e anuais nas precipitações do presente e do passado, considerando a maioria das suas interações, explicaram em parte, as variações encontradas tanto na riqueza de espécies como na emergência de plântulas. Considerando os sete anos, tanto a riqueza de espécies como a emergência de plântulas foram significativamente maiores no ano I. Analisando isoladamente a sazonalidade, a riqueza de espécies foi semelhante entre as estações climáticas. No entanto, a emergência de plântulas foi maior na estação seca. A análise do GLM também demonstrou que a precipitação do ano anterior e do ano corrente explicaram 4,2\% e $3.1 \%$ das diferenças encontradas na riqueza de espécie e na emergência de plântulas respectivamente. Vale salientar que, tanto para a riqueza quanto para a emergência de plântulas, todas as interações entre as variáveis analisadas neste estudo apresentaram efeito significativo, mas 
para algumas interações esta significância foi muito baixa, chegando a menos de $1 \%$.

A composição florística, riqueza de espécies e emergência de plântulas encontradas no banco de sementes do solo, são afetadas pelas variações sazonais e anuais das precipitações do presente e do passado, confirmando a hipótese. A maioria dos trabalhos sobre o banco de sementes do solo de ambientes secos demonstra que a pluviosidade influencia positivamente a composição e riqueza de espécie, além do número de sementes que chegam ao solo (WANG et al., 2005, WILLIAMS et al., 2005). Por exemplo, anos com maior total pluviométrico podem auxiliar no aumento da reprodução das plantas e consequentemente no número de sementes produzidas que são dispersas para o solo (WANG et al., 2005; FACELLI et al., 2005).

No entanto, neste estudo, considerando isoladamente a variação sazonal, foi constatado que o número de espécies encontrados no banco do solo foi semelhante entre as estações climáticas. Mas a composição florística diferiu significativamente entre estações e o número de sementes que germinaram do banco foi maior na estação seca em comparação com a estação chuvosa. Outras pesquisas descrevem que a densidade de sementes e a riqueza de espécies são maiores em períodos secos (ONAINDIA e AMEZAGA, 2000; TRABA et al., 2006). Segundo os autores a elevada densidade de sementes no período seco está relacionada à persistência do banco de sementes do solo e, por conseguinte, ao acúmulo da produção de sementes do ano anterior (ONAINDIA e AMEZAGA, 2000). E em alguns locais, a densidade de sementes no solo é maior no verão, devido ao pico de emergência de plântulas na estação subsequente (TRABA et al., 2006).

\section{Conclusões}

A composição florística, riqueza de espécies e a emergência de plântulas encontradas no banco de sementes do solo são influenciadas pela variação temporal encontradas em ambientes secos. Além disso, foi possível constatar que o banco de sementes do solo da vegetação de caatinga é formado com o auxílio das variações na precipitação.

\section{Referências}

ARAÚJO, V.K.R.; SANTOS, D.M.; ARAÚJO, E.L. Diferenças no banco de sementes de Delilia biflora (L.) Kuntze entre duas áreas de caatinga (antropizada e preservada) no nordeste do Brasil. 
Terra (Qualidade de vida, Mobilidade e segurança nas cidades). (Org) Giovani Seabra. Editora universitária UFPB, 2013.

FACELLI, J. M.; CHESSON, P.; BARNES, N. Differences in seed biology of annual plants in arid lands: a key ingredient of the storage effect. Ecology 86(11): 2998-3006, 2005.

ONAINDIA, M.; AMEZAGA, I. Seasonal variation in the seed banks of native woodland and coniferous plantations in Northern Spain. Forest Ecology and Management 126: 163-172, 2000.

SANTOS, D.M.; SILVA, K.A.; ALBUQUERQUE, U.P.; SANTOS, J.M.F.F.; LOPES, C.G.R.; ARAÚJO, E.L. Can spatial variation and inter-annual variation in precipitation explain the seed density and species richness of the germinable soilseed bank in a tropical dry forest in north-eastern Brazil? Flora 208 : 445-452, 2013.

SILVA, K.A.; SANTOS, D.M.; SANTOS, J.F.F.; ALBUQUERQUE, U.P.; FERRAZ, E.M.N.; ARAÚJO, E.L. Spatio-temporal variation in a seed bank of a semi-arid region in northeastern Brazil. Acta Oecologica 46: 25-32, 2013.

TRABA, J.; AZCÁRATE, F.M.; PECO, B. The fate of seeds in Mediterranean soil seed bank in relation to their traits. Journal of vegetation science 17: 5-10, 2006.

WANG, S.M.; ZHANG, X.; LI, Y.; ZHANG, L.; XIONG, Y.C.; WANG, G. Spatial distribution patterns of the soil seed bank of Stipagrostis pennata (Trin.) de winter in the gurbantonggut desert of north- west ,China. Journal of arid environments 63:203-222, 2005.

WILLIAMS, P.R.; CONGDON, R.A; GRICE, A.C; CLARKE, P.J. Germinable soil seed banks in a 